\title{
Considering the role of life cycle analysis in holistic food systems research, policy, and practice
}

\author{
Andrew Berardy, ${ }^{a} *$ Thomas Seager ${ }^{b}$ \\ Arizona State University \\ Christine Costello ${ }^{\mathrm{c}}$ \\ The Pennsylvania State University \\ Christopher Wharton ${ }^{\mathrm{d}}$ \\ Arizona State University
}

Submitted October 6, 2019 / Revised December 10, 2019, and January 16 and February 4, 2020 /

Accepted February 6, 2020 / Published online June 30, 2020

Citation: Berardy, A., Seager, T., Costello, C., \& Wharton, C. (2020). Considering the role of life cycle

analysis in holistic food systems research, policy, and practice. Journal of Agriculture, Food Systems, and

Community Development, 9(4), 209-227. https://doi.org/10.5304/jafscd.2020.094.009

Copyright (C) 2020 by the Authors. Published by the Lyson Center for Civic Agriculture and Food Systems. Open access under CC-BY license.

\begin{abstract}
Researchers use life cycle assessment (LCA) to evaluate the environmental impacts of foods, providing useful information to other researchers, policy-makers, consumers, and manufacturers. However, LCA is ill-equipped to account for desirable, often normatively valued, characteristics of food systems, such as redundancy, that could be considered more sustainable from a resilience perspective. LCA's requirement of a functional unit also causes methodological bias favoring efficiency over resilience and other difficult-to-quantify prop-

a* Corresponding author: Andrew Berardy, Swette Center for Sustainable Food Systems, Arizona State University.

Dr. Berardy is now in the Department of Environmental Nutrition, Loma Linda University; Loma Linda, California 92350 USA; AndrewBerardy@,llu.edu

b Thomas Seager, School of Sustainable Engineering and the Built Environment, Arizona State University; 781 South

Terrace Road, Floor 3; Tempe, Arizona 85287 USA; +1-480-965-3589; Thomas.Seager@asu.edu
\end{abstract}

erties. This efficiency bias results in favorable evaluations of conventional production techniques and plant-based foods since they typically have the lowest impacts per unit of output when compared to alternative agriculture systems and animal-based foods. Such research findings may drive policymakers as well as consumers to prefer the more efficient options, with the possible outcome of diminishing resilience. This research and policy commentary explains why complementary assessment methodologies are necessary for comprehensive sustainability assessments that support

${ }^{\mathrm{c}}$ Christine Costello, Department of Agricultural and Biological Engineering and The Rock Ethics Institute, The Pennsylvania State University; University Park, Pennsylvania 16802 USA; chriscostello@psu.edu

${ }^{\mathrm{d}}$ Christopher Wharton, Radical Simplicity Lab, College of Health Solutions, Arizona State University; 550 North 3rd Street, Floor 5; Phoenix, Arizona 85004 USA; +1-602-4961727; Christopher.Wharton@asu.edu 
researchers, policy-makers, and other relevant stakeholders in decision-making for food systems sustainability. In addition to LCA, researchers examining food systems sustainability issues should consider integrating other frameworks and methods such as life cycle sustainability assessments, sustainable materialism, backcasting and scenario building, and food systems assessments to help generate a holistic understanding of the systems being analyzed.

\section{Keywords}

Food Systems, Life Cycle Assessment, Research and Policy, Sustainability

\section{Introduction}

Food systems are necessary for the survival and health of humanity, but they can also pose risks. A key purpose of food systems is to transform raw materials into foods with sufficient levels of nutrients. The goal is to support health outcomes within biophysical and sociocultural contexts in which food is also pleasure, income, culture, and tradition (Sobal, Khan, \& Bisogni, 1998). Food systems should also provide food security by ensuring availability, access, and utilization of food (Ericksen, 2008). Regardless of the framing of their operations and preferred outcomes, food systems are a significant contributor to environmental and related health problems (Campbell \& Campbell II, 2006; Eakin, Connors, Wharton, Bertmann, Xiong, \& Stolzfus, 2017; Food and Agriculture Organization of the United Nations [FAO], 2006; Weber \& Matthews, 2008). Pursuing sustainability requires consideration of if and how food systems operations can be maintained consistently in the future in order to provide future generations with outcomes similar to those demanded today (Brundtland, 1987).

Both policy-makers and consumers play important roles in shaping the future of food systems as manufacturers react to laws, regulations, and consumer demand. This manuscript describes a commonly used tool, life cycle assessment (LCA), that can be used to inform those decisions, before moving on to describe limitations of this approach in isolation. Other methodologies that can be strategically combined with LCA to provide a more comprehensive understanding of sustainable choices are then described. Consideration of such a combinatorial approach is timely because LCA is now widely used in food system analyses despite its unique methodological challenges. Some of these challenges include difficulty in accounting for the complexity and variability of production systems and consumption decisions, as well as an efficiency bias caused by the necessity of utilizing a functional unit. LCA is also poorly suited to address some important environmental and health concerns generated by modern food systems. In fact, LCA tends to support the refinement of existing systems, perpetuating the status quo rather than encouraging food systems transformation. Growing food-related trends, such as the proliferation of highly processed plant-based foods, and debate regarding the utility and danger of genetic engineering, ensure that LCA remains valuable for assessing specific claims of environmental superiority in relevant impact categories. However, researchers should acknowledge that there remain sustainability and resilience concerns that can only be addressed through other methodologies as part of a mixedmethods design. Such an approach can help advance solutions that satisfy a broader range of concerns rather than LCA's traditional focus on efficiency.

\section{Life Cycle Assessment}

LCA is the systematic quantification of the environmental impacts caused by the inputs required and outputs generated throughout the stages of a product's life cycle, including extraction, production, distribution, use, and disposal. LCA can be used to evaluate and compare foods and their production systems. It also attempts to capture all flows between the technosphere (human-made manufacturing processes) and biosphere (the natural world or ecosystem). These flows are then characterized and normalized in an effort to translate them into comparable and meaningful environmental and resource-related impacts. Researchers turn to LCA to quantitatively assess the sustainability of a given product, production system, or consumer choice (Andersson, 2000; Jungbluth, Tietje, \& Scholz, 2000; Roy et al., 2009). 


\section{LCA and Food Systems}

LCA's of foods and diets are intended to inform consumers, producers, policy-makers, and other stakeholders and enable them to make better choices by comparing the environmental impacts of products. Applied to food systems, LCA can provide evidence to help guide policy-making in some specific circumstances, such as evaluating the impacts of agricultural commodities or establishing carbon tax for individual foods (Gava et al., 2019). Although common metrics used in food LCA include global warming potential (GWP), eutrophication potential, land use, and water use, there are additional important environmental impacts of concern such as biodiversity loss and health impacts associated with dietary patterns, both of which are rarely if ever considered in food LCA (de Vries \& de Boer, 2010; Roy et al., 2009). LCA frequently focuses on agricultural and farm-level production, as these stages are generally the largest sources of greenhouse gas emissions, eutrophication potential, and land use (de Vries \& de Boer, 2010; Heller \& Keoleian, 2003; Weber \& Matthews, 2008).

\section{Main Types of LCA for Food}

Attributional LCA (ALCA) of foods typically characterizes the environmental impact attributed to a given functional unit (i.e., the quantified basis of comparison between environmental impacts of alternatives serving similar purposes) produced in an existing system. However, a detailed analysis of the current system does not serve the purposes of those who seek more than incremental change. The type of LCA known as consequential LCA (CLCA) is perhaps better suited for this goal because it estimates the environmental impact of a change in output of the functional unit. ALCA is therefore suitable for assessing the environmental burden of a product in a status-quo situation, i.e., the production of agricultural commodities, whereas CLCA is suitable for assessing environmental consequences of a change in demand (Thomassen, Dalgaard, Heijungs, \& De Boer, 2008). CLCA also is more capable of capturing complexity, especially when coupled with the use of system expansion in which the inputs and outputs of a product are ascribed entirely to it, but the system is expanded to account for products displaced by co-products of the main product, sometimes creating feedback loops as a result. One example of this is the "soybean-rapeseed-loop," in which soybean meal has the coproduct of soy oil, which displaces the need for rapeseed oil, which in turn is a co-product with rapeseed meal, which then requires its own system expansion in which it displaces soybean meal, starting the loop again (Dalgaard et al., 2008) (Dalgaard et al., 2008). Co-production like this, as well as natural processes, creates challenges for LCA of food.

\section{Challenges in Food LCA}

There are some unique aspects of food production systems that pose challenges for food LCA. First, agricultural systems do not lend themselves to simple point estimates or even reliable longitudinal averages because they are subject to high degrees of variability. Second, agricultural production blurs the boundary between the biosphere and the technosphere in ways that make identification and quantification of the material and energy exchanges required by LCA ambiguous. Finally, food products defy traditional evaluation using a single functional unit because individual foods are complex mixes of nutrients, tastes, and textures that can serve fundamentally different purposes in different contexts.

\section{Variability}

Completing a life cycle inventory (LCI) through data collection in the field is necessary to perform an LCA. However, geographic and seasonal variability may cause change over time and across similar but geographically dispersed systems. Farming is geospatially distributed across a wide variety of ecosystems and biomes, causing variability in data collected for inventories (Notarnicola, Sala, Anton, McLaren, Saouter, \& Sonesson, 2017). There is heterogeneity at every stage of production in a food system, including temporal and seasonal changes to temperature, rainfall, and sun exposure, soil fertility, seed characteristics, harvest practices, and distributor and consumer preferences. Variability, therefore, limits the certainty and accuracy of applying LCA results calculated at a particular time and place to the same product produced in a different times and places. 
Blurred Lines

One of the fundamental, albeit largely unstated hypotheses of Industrial Ecology, a discipline commonly associated with LCA, is that economic production takes place exclusively in the technological systems that are the product of the industrial revolution (Seager \& Theis, 2002). The standard LCA practice of compiling an LCI of the material or chemical and energetic exchanges between systems assumes that an unambiguous separation of the biosphere and the technosphere can be drawn, which is typically considered the system boundary. That is, the scope of the LCI consists entirely of activities occurring within the technosphere and exchanges to and from the biosphere. However, agriculture blurs the line between the biosphere and technosphere through human intervention into ecosystems that utilizes biological processes alongside technology and artificial inputs.

Even in industrial agriculture production, including monoculture crops and confined animal feeding operations (CAFOs), variations based on soil, climate, and watershed characteristics exist, and it is unclear precisely where the system boundary should be drawn. In these cases, some ecosystem services such as aquifer replenishment, animal habitats, and an agrarian aesthetic are provided, but not necessarily quantified or clearly attributable to the production system. More complex systems of co-production that utilize crop rotation rely on high levels of expertise and more extensive manual labor. LCA is ill-equipped to disaggregate and allocate the impacts of this more extensive manual labor across co-products in a dynamic and interconnected agricultural system. Further, many benefits ascribed to alternative agricultural systems, such as better nutritional characteristics and taste, soil health, and long-term productivity of the land, are not captured by typical LCA metrics. Food always involves the co-production of other products, such as ecological habitat, which makes difficulties in the allocation of burdens inevitable.

Aquaponics and aeroponics, as well as cultured meat production, are possible exceptions where a controlled environment allows for a clearer boundary between technology and nature; however, they do not represent typical farming practices. Even in these cases, at least some aspect of the production model relies on natural processes that are likely to have co-products. For example, cultured meat production byproducts may include alanine, ammonia, and lactate from the corn and soy used in providing glucose and amino acid (Mattick, Landis, Allenby, \& Genovese, 2015). Advances in genetic engineering blur the boundary even further by treating nature as a design space, indefinitely extending the technosphere.

\section{Wild LCA}

Wild-grown and -harvested or -caught foods further complicate the boundary between the biosphere and the technosphere. In many cases, these foods exist in nature without any intentional inputs, but when humans take the animals or plants out of their ecosystems, the impact of the disruption of that ecosystem must be accounted for. An LCA including wild-caught cod noted a need for improved indicators for impacts of over-fishing, emissions from boats, use of antifouling agents to maintain equipment, and disturbances to the seafloor ecosystem for LCA to more accurately capture environmental impacts of wild fishing (Ellingsen \& Aanondsen, 2006). Cod grow and procure food independently, but humans expend resources to find and capture them to be processed and sold for consumption, which interrupts a nonhuman food web. This disruption to larger-scale patterns occurs from more common agricultural practices as well.

\section{Beyond the Farm}

While all human structures or modifications to the land surface result in disruption to ecosystem services, agricultural activities present additional issues that are not well captured by existing LCA inventory and impact characterization methods. Beyond individual farms and crops, swaths of land are characterized by vast fields of corn and soy. These vast fields change the landscape for entire communities and watersheds, such as the Mississippi River basin, about $58 \%$ of which was used as cropland as of 2000 (Goolsby \& Battaglin, 2000). The proper scale for assessment is difficult to determine in such cases where an individual unit of operation exists amid many other units engaged in the same production. In the case of fertilizer, eutrophication 
is the potential environmental impact of concern. Fertilizer applied within the Mississippi River Basin can cause eutrophication leading to an algae bloom and hypoxia that impacts both a local stream and the Gulf of Mexico (Rabalais, Turner, \& Wiseman, 2002).

When considering eutrophication potential, many LCA studies calculate a nutrient balance according to the physical boundary of the farm itself. This typically includes fertilizer, crop-based nitrogen fixation, nutrient content of feed and imported livestock, and release of nitrogen from decomposition; however, it may or may not include associated inputs and impacts from off-farm activities

(Costello, Xue, \& Howarth, 2015). Estimates of eutrophication potential can be based on converting total nutrient inputs using a normalization factor, using physical models to estimate nutrient fluxes, or applying empirically derived multipliers to the net nutrient farm-balance (Costello et al., 2015). This variety of approaches demonstrates that there is not a consistent and correct way to account for eutrophication potential across studies. This problem is largely a result of the difficulty and ambiguity in delineating a clear system boundary for an agricultural production system (Morelli et al., 2018). There is a tendency to shrink system boundaries rather than expand them, as this allows for easier data collection and more certainty in the assessment performed.

\section{Post-harvest LCA}

Modeling limitations and lack of data availability hinder post-farm gate analysis of food manufacturing, distribution, consumption, and disposal stages, meaning that many food LCA's are only cradle to gate. Increasingly sophisticated post-harvest technologies complicate food supply chains and cause higher environmental burdens for later stages of the food life cycle. Processes including packaging, refrigeration, distribution, and cooking are potentially significant. However, they are not captured by most food LCA studies, thereby ignoring a potentially large portion of the total life cycle environmental impact. Although it is more challenging, time-consuming, and expensive to perform, food LCA researchers should make an effort to assess the environmental burdens of more complex food products, especially those making claims regarding their environmental superiority to more traditional foods. It is also important to ensure comparisons are being made on as reasonably fair a basis as possible.

\section{Functional Units and Food}

Functional units are based on the obligatory properties of items or systems being analyzed, without which the item would not fulfill its intended purpose (e.g., a beverage container should not leak) (Weidema, Wenzel, Petersen, \& Hansen, 2004). Using a consistent functional unit, such as mass (e.g., 1 kilogram of a product) allows comparison of environmental impacts of products across different production systems by providing a common basis for quantifying the necessary inputs and outputs to produce equivalent functional units of the product.

When considering the obligatory properties of food, assigning a functional unit is difficult because foods typically serve multiple purposes, which also vary based on the person consuming them. For example, both a tomato and banana provide the nutrients potassium and vitamin $\mathrm{C}$ along with calories. However, only one is used in making pasta sauce, and only one is used in a banana split because they have very different flavors, textures, and appearances. Comparing diets or meals becomes even more complicated due to a larger number of potential reasons for food choices as well as cobenefits from eating certain foods together. The experience of the food, the culture surrounding it, and the direct economic support of community can be more important to the consumer than any other characteristic. In the face of these myriad possibilities, researchers often default to a seemingly neutral weight-based functional unit, which is useful for optimizing individual products or comparing similar products, but not for comparisons between products serving essentially different purposes. The comparison of alternatives based on a common functional unit is essential for LCA to work, but also results in an emphasis on efficiency in fulfilling that functional unit.

\section{Functional Units and Efficiency Bias}

Examination of the LCA methodology reveals that its structure inherently favors efficient resource us- 
age over other priorities. The use of LCA to examine existing production systems without consideration of alternative consumption possibilities strengthens this efficiency mindset (Garnett, 2014). Choosing a functional unit implies that all other aspects of a system should be optimized based on this primary purpose of the product. Impacts not directly tied to the functional unit on a quantitative basis (e.g., biodiversity) are at risk of being lost in the assessment, or may only be captured indirectly through other metrics (e.g., land use) (Kloepffer, 2008).

LCA's emphasis on efficiency was useful for its original purpose, which was to systematically improve mature manufacturing industries such as automobiles or petrochemicals (Seager \& Theis, 2002). However, functional units frequently do not account for various, often intangible, qualities that people derive from consuming food, nor do they account for characteristics increasing the resilience of a system, both of which may be justification for lower efficiencies of production systems. For example, when considering a food systems transformation perspective, GWP is just one of many characteristics of the systems, which include the calories, micronutrients, fiber, fuel, labor, cultural contribution, status symbols, liquid assets, and resilience provided by the systems, making the functional unit an inadequate measure of success or sustainability (Garnett, 2014). Some LCA researchers have attempted to include elements that focus on the preservation of natural systems, such as biodiversity (Curran et al., 2010). However, as long as impacts are normalized based on a common quantifiable functional unit, as is necessary for LCA, the focus will remain on efficiently fulfilling the obligatory properties of the functional unit, potentially at the expense of a less sustainable overall system that might be prioritized from a resilience perspective. LCA therefore is not adequate for a holistic sustainability evaluation of alternatives, as it fails to account for other priorities such as food security, equity, and resilience. The next section serves as an overview and reminder of the multitude of environmental challenges presented by and to food systems, some of which are not captured by LCA.

\section{Environmental Impacts from Food Systems}

Due largely to reliance on fossil fuels and industrialized agriculture, humanity has exceeded Earth's "safe operating space" for multiple planetary boundaries (e.g., disturbance to nitrogen and phosphorus cycles from fertilizer and cultivation of leguminous crops) (Rockström et al., 2009).

Land-use change resulting from agricultural production is responsible for about $75 \%$ of global deforestation (Vermeulen, Campbell, \& Ingram, 2012). Food systems account for $19-29 \%$ of global greenhouse gas emissions, including about half of methane emissions, much of which comes from ruminant livestock's digestion causing enteric fermentation (i.e., microorganisms breaking down carbohydrates in the rumen, the cow's first stomach, creating methane that is typically burped out) (Lassey, 2007; Vermeulen et al., 2012).

Agricultural run-off of excess nutrients (e.g., nitrogen and phosphorus) from agricultural production in the Mississippi River Basin is transported to the Gulf of Mexico, resulting in eutrophication (excessive nutrients in water) and subsequent hypoxia. Hypoxia is the condition of having low or depleted oxygen. In this case, hypoxia is caused by a eutrophication-induced algae bloom leading to the overgrowth and subsequent death and decomposition or digestion of phytoplankton by fish, the results of which sink to the bottom of the Gulf waters where it is decomposed by aerobic bacteria, depleting oxygen. The depleted oxygen causes fish to leave the area and bottom dwellers unable to leave die, leaving a lifeless area known as the Gulf of Mexico dead zone (Rabalais et al., 2002; Xue \& Landis, 2010).

Global warming will result in regions with less productive crops that require more resource inputs but have a higher likelihood of failure, resulting in weakening food system resilience, and increase the potential for cascading system failures across the food-energy-water nexus (Berardy \& Chester, 2017). Livestock production is an especially significant contributor to the environmental problems listed above due to its massive and growing scale, inefficiency in conversion of crops to protein, high land and water use, tendency to overgraze, contribution to biodiversity loss from mono-cropping to feed livestock, and high levels of associated green- 
house gas emissions (FAO, 2006). Paradoxically, as people gain affluence and can afford more meat, their tastes change, and their demand for animalbased food products grows considerably

(McMichael, 2001).

In terms of food use, about one-third of all food produced is wasted. This phenomenon exacerbates challenges across food systems by increasing the need for production while simultaneously directly contributing to methane emissions from food rotting in landfills (FAO, 2011; U.S. Environmental Protection Agency, n.d.). Despite this, many people suffer from food insecurity around the world, including an estimated 2 billion people with micronutrient deficiencies (Gödecke, Stein, \& Qaim, 2018).

Adding to these challenges, food systems are under pressure to provide more food while making lower environmental impacts as the global population continues to rise (Godfray et al., 2010). Even further disconnected from LCA than such environmental impacts, but still of great importance to sustainable food systems, are impacts on human health, as explained in the next section.

\section{Health Impacts from Food Systems}

Food systems, as currently designed, encourage unhealthy eating habits, which lead to negative health outcomes and threaten sustainability (Willett et al., 2019). This problem is typically associated with developed nations but continues to spread globally across developing nations. The spread is largely a result of trends including increases in processed and high-fat, high-energy-density foods, more eating away from home, and higher intake of oils and sugary beverages, as well as reduced physical activity and increased sedentary behavior (Drewnowski \& Popkin, 1997; Du, Mroz, Zhai, \& Popkin, 2004). Westernized diets are associated with an increased rate of diet-related diseases (Campbell \& Campbell II, 2006). The Western diet's overconsumption of fat, cholesterol, protein, sugar, and salt, as well as processed and fast foods, increases rates of obesity, metabolic syndrome, and cardiovascular disease, and may also promote autoimmune disease (Manzel, Muller, Hafler, Erdman, Linker, \& Kleinewietfeld, 2014).

The mismatch between human physiology and
Western dietary patterns and lifestyle underlies the growing levels of diseases (e.g., "coronary heart disease, obesity, hypertension, type 2 diabetes, epithelial cell cancers, autoimmune disease, and osteoporosis," (Carrera-Bastos, Fontes-Villalba, O'Keefe, Lindeberg, \& Cordain, 2011)) that are rare or absent in hunter-gathering and non-Westernized populations. Observations from countries transitioning from traditional to Westernized diets support the association between the Western diet and negative health impacts, even within a population maintaining a primarily vegetarian diet. The overall incidence of noncommunicable diseases in India, including an obesity epidemic, rose as the country shifted toward a Western diet, including decreased whole plant food consumption and increased consumption of refined carbohydrates, fast food, snacks, processed foods, and fried foods (Singh et al., 2014).

In addition to physical health problems like obesity, the Western diet also contributes to cognitive impairment and hippocampal dysfunction, including Alzheimer's disease (Kanoski \& Davidson, 2011). A Western diet is also associated with higher indications of depression and anxiety (Jacka et al., 2010).

While LCA studies exist that compare environmental impacts of dietary preferences, their consideration of health impacts rarely extends beyond ensuring foods with similar nutrient characteristics are being compared. They typically do not address Westernized compared to traditional diets in any meaningful way but rather compare omnivorous to vegetarian diets (Baroni, Cenci, Tettamanti, \& Berati, 2007; Risku-Norja, Kurppa, \& Helenius, 2009; Scarborough et al., 2014). A recent trend that attempts to counter the negative health and environmental consequences of Westernized meatheavy diets is the rise in the consumption of plantbased foods.

\section{Plant-based Trends}

Increasing environmental awareness along with health and ethical concerns inspired rapid growth in the consumption of plant-based foods in 2018 that was ten times the overall rate of growth for all foods (Plant Based Foods Association, 2018a). New meat analogs such as the Beyond Burger 
drove US\$670 million in growth, and other dairy alternatives drove $\$ 697$ million in growth. On the other hand, more traditional plant-based foods like tofu and tempeh drove only US\$108 million in growth (Plant Based Foods Association, 2018b).

However, the amount of processing and technology required for some modern plant-based foods calls into question whether or not they appreciably lessen impacts on the environment, or people's health, compared with minimally processed animal-based foods. The plant-based Impossible Burger is a common target, in part due to the fact it uses genetically engineered ingredients, which itself is controversial (Robinson \& Antoniou, 2018; Uzogara, 2000). Fortunately, LCA is well-suited to investigate quantifiable environmental claims of competing products serving similar functions and can help identify the environmental consequences of choosing one over another.

\section{Tradeoffs in LCA}

When employed appropriately, with an understanding of its limitations, LCA can prove useful as a tool for evaluating alternatives. It can even capture some, but not all, of the tradeoffs between competing visions for sustainable food systems. Analysis of highly processed foods that are the products of technologically advanced production methods compared to minimally processed foods from production systems relying on more substantial inputs of natural resources (e.g., plant-based meat analogs compared to biodynamic meat) could help highlight potential impacts of such competing alternatives. Figure 1 provides a visual representation of the potential tradeoffs made when shifting between high-intensity manufacturing and high-intensity farming to produce food.

\section{LCA Limitations}

As demonstrated in Figure 1, there are limited LCA's of more complex manufactured food products, restricting possible comparisons between foods available for consumption. This problem is compounded by the fact that new products are continuously being introduced, and many food items have dozens of ingredients, most of which do not have existing LCA data. Further, many food products' ingredients are intentionally masked through vague labeling and ingredients lists, and their exact composition is proprietary data. Products can also be reformulated as manufacturers try to save money on ingredients or appeal to a new trend, changing the ingredients and invalidating the LCA work performed. Unfortunately, even among products for which LCA exists, many have not been evaluated in terms of their sustainability impacts from a broader environmental or human health perspective. Doing so requires tools in addition to LCA.

\section{LCA and Sustainable Food Systems}

Despite the value of a quantitative approach to evaluating alternatives, LCA alone is insufficient to determine the most sustainable option among alternatives because the methodology fails to capture other values that are still relevant. Although researchers have yet to reach a consensus regarding what the fundamental problems facing food systems are, what components of food systems are important to sustain, or what the ideal solutions are, some common priorities include food security, efficient resource usage, environmental preservation, and equity (Eakin et al., 2017).

The perspectives of efficiency-oriented, demand restraint, and food systems transformation reflect three emerging approaches to food systems sustainability that differ based on humanity's relationship with nature and technology (Garnett, 2014). ALCA supports an efficiency-oriented perspective since it examines the optimization of existing systems. CLCA is most supportive of a demand restraint perspective as it can help imagine alternative scenarios, including those with different consumption patterns (Garnett, 2014). However, food systems transformation requires consideration of components outside the scope of existing LCA methodologies, as it must account for the inequality and imbalance between actors within food systems and strive towards social justice (Garnett, 2014). Similarly, debates regarding controversial approaches to changing food systems such as genetic engineering cannot be resolved using LCA results alone. However, LCA can be useful to investigate the validity of claims against alternative agriculture, such as decreased yields and increased resource us- 


\section{Figure 1. Greenhouse Gas Emissions ( $\mathrm{kg} \mathrm{CO}_{2}$ equivalents) from Selected Foods.}

Most LCA evaluates commodities with minimal manufacturing processes. Value ranges are from references listed in the key (Berlin, 2002; Carlsson-Kanyama, 1998; Cederberg \& Stadig, 2003; Dalgaard et al., 2008; Hamerschlag \& Venkat, 2011; Kim, Dale, \& Jenkins, 2009; Leinonen, Williams, Wiseman, Guy, \& Kyriazakis, 2012; Mejia et al., 2018; Mollenhorst, Berentsen, \& De Boer, 2006; Sanfilippo, Raimondi, Ruggeri, \& Fino, 2012; Tuomisto \& de Mattos, 2011; Williams, Audsley, \& Sandars, 2006).

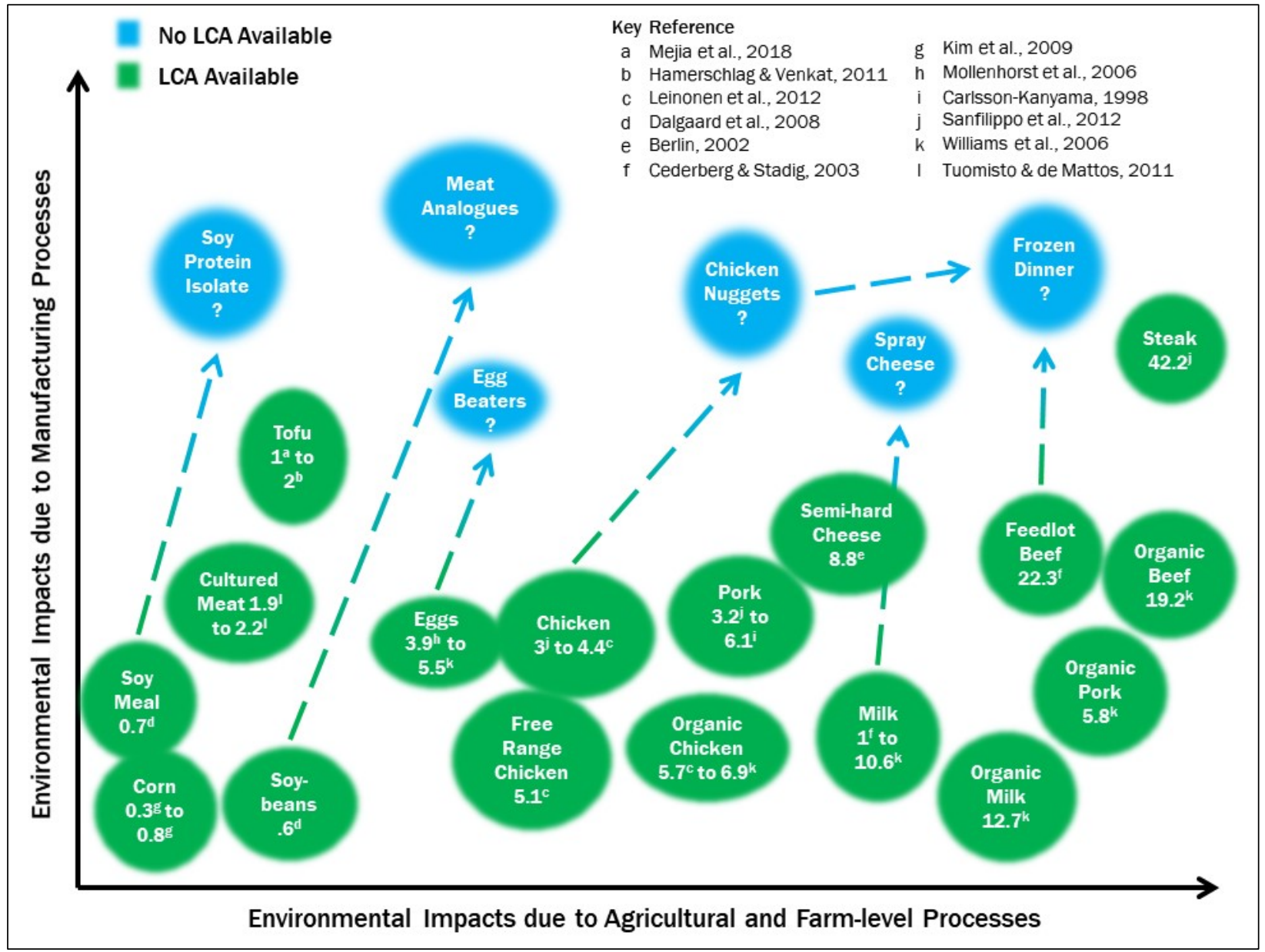

age in organic compared to conventional agriculture (Chatzisymeon, Foteinis, \& Borthwick, 2017; Foteinis \& Chatzisymeon, 2016).

\section{Utility of LCA}

LCA's greatest utility may be in ensuring there is a quantifiable justification behind assumptions that lead to behavioral changes to promote environmental sustainability, as this protects against the risk that counterproductive behaviors may be prioritized. For example, an emphasis on local food production and consumption to reduce food miles has far less of an impact on greenhouse gas emis- sions than reducing red meat consumption (Weber \& Matthews, 2008). Without this knowledge, consumers might choose to purchase locally raised beef with the incorrect impression that it has a lower GWP than imported chicken or vegetarian meat analogs. However, this does not invalidate the importance of local foods for other reasons, which can be investigated and demonstrated using other assessment tools. Research has shown, for example, that participating in community supported agriculture (CSA) may cluster with other sustainability-oriented behaviors, such as recycling and composting (MacMillan Uribe, Winham, \& 
Wharton, 2012). While, ostensibly, these activities contribute further to sustainability, LCA can only provide an assessment of quantifiable environmental tradeoffs.

\section{Addressing Resilience}

If efficiency is the dominating characteristic driving LCA, a countervailing concern is resilience. How tensions between such priorities are resolved will drive the future of the global food system, which requires accounting for competing values reflected therein (Berardy, 2015). Sustainability problems can also be characterized as wicked problems, in that they are difficult to formulate, have multiple, incompatible solutions, have open-ended timeframes, are novel or unique, and are subject to competing value systems or objectives (Seager, Selinger, \& Wiek, 2012). One tradeoff that sometimes must be made is between efficiency and resilience, as optimization for efficiency often reduces the capacity for resilience (Korhonen \& Seager, 2008). In fact, although it is inefficient, redundancy is a necessary component of a resilient system, as it increases the system's capacity to survive and adapt to disturbances (Worstell \& Green, 2017).

Integrating resilience concerns into LCA is a complicated endeavor due to the inherent bias towards efficiency resulting from LCA methodology. Prominent frameworks share eight common qualities that define a resilient system. These qualities include being independent, yet connected, locally self-organizing, accumulating reserves and infrastructure, establishing back-ups and redundancy, fostering diversity and complementarity, encouraging conservative innovation, integrating with ecology to minimize imported and manufactured inputs, and embracing disturbance and transformation (Worstell \& Green, 2017). The optimization orientation of LCA means that even resilienceoriented constraints will be reduced to the most expedient way to achieve their stated minimum requirements (e.g., the minimum redundancy required for a resilient system).

Although some resilience characteristics, such as diversity, may complement it, efficiency itself drives rigidity in contrast to resilience, making these opposing forces (Pizzol, 2015; Worstell \& Green, 2017). Specifically, in agriculture, fertilizer and pesticide application, as well as other modern production methods to optimize yield and efficiency, can undermine the provision of ecosystem services, biodiversity, and, ultimately, the long-term resilience of the soil and production system (Bennett et al., 2014). These priorities parallel the ethical tension in sustainability between preserving resources for the future by making sacrifices today and meeting the needs of all people in the present (Seager et al., 2012).

Exploration of these perspectives is necessary to achieve sustainable food systems that satisfy both practical and normative concerns. Unfortunately, many sustainable agriculture definitions and assessment tools focus on a range of specified criteria rather than taking a resilience approach. A resilience approach would focus on the ability of a system to withstand and overcome disturbance while maintaining its functionality (Worstell \& Green, 2017). Ultimately, relying solely on LCA with its focus on efficiency will only serve to reinforce optimization of the status quo, decreasing resilience and increasing the risk of collapse. A more sophisticated understanding that integrates resilience concerns is required.

\section{Improving LCA and Related Studies}

\section{Recognition of Problems and Solutions}

LCA practitioners have a responsibility for transparency in modeling and reporting results, which includes acknowledging the limitations of LCA. However, they can also work to improve the tool to address some of the challenges outlined here. The challenges identified and some potential solutions are summarized in Table 1 and discussed below.

\section{Nutrient Based Dietary Comparisons}

The challenges associated with determining an ideal functional unit can be partially alleviated by providing multiple independent functional units based on quantifiable and justifiable obligatory properties. Translating impacts calculated with weight as a functional unit to impacts with nutrients as a functional unit is straightforward since the equivalent impacts are based on the amount of weight necessary to achieve the nutrient quantity established as 
Journal of Agriculture, Food Systems, and Community Development

ISSN: 2152-0801 online

https://www.foodsystemsjournal.org

Table 1. Several Potential Solutions to Deal with Challenges Facing Food LCA

\begin{aligned} & \hline Food LCA Challenges Potential Solutions \\ & \hline Blurred boundaries Transparent methodology, recognition of issue \\ & Appropriate functional unit / LCA of diets Multiple functional units, Stochastic Multi-Attribute Analysis \\ & Geospatial variability Geographic Information System enabled LCA, fate and transport models \\ & LCA bias towards efficiency Utilize mixed methods \\ & Integrating qualitative methods Life cycle sustainability assessment, food systems assessments, sustainable \\ & materialism, backcasting, and scenario-building \\ & \hline\end{aligned}

a new functional unit. This allows researchers to present the range of impacts associated with products being compared in a way that demonstrates to the reader the sensitivity to the comparison basis. A recent publication demonstrated how even an advanced assessment of protein quality could be integrated into the interpretation of LCA results (Berardy, Johnston, Plukis, Vizcaino, \& Wharton, 2019). In contrast with traditional LCA analysis, the integration of protein quality in the assessment resulted in some animal-based proteins being compared favorably with plant-based proteins (Berardy et al., 2019).

\section{Stochastic Multi-Attribute Analysis}

Multicriteria decision making is another option for more effective delivery of results when preferences are known or can be estimated. Stochastic multi-attribute analysis for life cycle impact assessment (SMAA-LCIA) performs internal normalization to facilitate tradeoff identification across multiple perspectives simultaneously and provide a rank ordering of alternatives (Prado-Lopez et al., 2014). The challenge of how to incorporate sensory and cultural preferences and values remains.

\section{GIS-LCA}

LCA can also incorporate geographical information system (GIS) enabled assessment to allow for better assessment of biodiversity and land use impacts (Geyer, Lindner, Stoms, Davis, \& Wittstock, 2010). Due to regional variability, impacts such as eutrophication potential need to account for the watershed in which the production occurs, and if applicable, the physical landscape of the agricultural production site, including presence or absence of buffer strips. Variations in regions are reflected in the results of GIS-enabled LCA, which finds significant variations in environmental impacts between locations when examining corn production across five U.S. states (Rodríguez, Ciroth, \& Srocka, 2014).

\section{Fate and Transport Modeling}

Addressing geospatial variability in LCA may be improved by the utilization of fate and transport models to estimate how inputs are dispersed in the surrounding ecosystem (Morelli et al. 2018). However, the application of fate and transport models to current practices will only point out hotspots for implementation of best management, not assist with resolving differences between efficiency and resilience. Fate and transport models demonstrate how a conventional farm compares to a novel food production approach that meets resilience values (e.g., permaculture) and/or can show annual variability in actual export of nutrients from the farm given climate variation. This model could highlight differences in how these systems interact with physical systems represented within the models, which may help to clarify the pros and cons of these relative approaches. While integrating these approaches with LCA can help address some of its challenges, a mixed-methods approach is required to perform a holistic sustainability assessment. Fortunately, there is a wide variety of established and emerging complementary methodologies that can be utilized.

\section{Complementary Methodologies}

LCA is just one tool of many that can be coupled with other forms of assessment to provide a more balanced and holistic analysis of a given product, production system, or consumer behavior. Sustain- 
ability evaluation needs multiple methodologies that capture the diversity of factors important to all stakeholder viewpoints involved. Complementary methodologies should fill the gaps in the assessment that LCA is ill-suited to address, including concerns regarding resilience, food security, equity, and alternative food systems, as well as the potential for transformation. There is a need for tools and frameworks to help consumers, policy-makers, and other stakeholders make informed decisions about dietary choices, recommendations, and food systems operations. Some tools and frameworks exist that can provide necessary information for these stakeholder groups. However, given the complexity of food systems and food-related policies and behaviors, it is likely that current assessment tools must be combined and improved in order to support more holistic decision-making. Because competing ethical and other normative concerns arise in relation to perceptions of food system sustainability (Eakin et al., 2017), tools used to evaluate aspects of food systems are often qualitative in nature or include mixed methods that employ both quantitative and qualitative approaches. Some examples of tools and concepts that are useful in representing a broader set of perspectives include applications of life cycle sustainability assessment (LCSA), food systems assessments, sustainable materialism, and backcasting and scenario-building. Through multiple combined methods and frameworks, researchers can provide a more holistic vision of the foods, production methods, or behaviors being evaluated and enable potential decision-makers to understand their consequences in a way that aligns with their own values.

\section{Life Cycle Sustainability Analysis}

Life cycle sustainability analysis (LCSA) expands on LCA by adding consideration of concerns beyond typical environmental burdens, including animal welfare and food security and by utilizing multiple simulation models at the animal, crop, and farm level. LCSA attempts to provide a more holistic analysis by broadening the scope and integrating models, but its application is still limited, and aspects of its practice remain unclear (Guinée et al., 2011). LCSA broadens and deepens the scope of LCA to include economic and social concerns, ad- dress sector-level instead of product-level questions, and examine physical, economic, and behavioral relations rather than just technological relations; however, it is still fairly uncommon and an evolving tool (Guinée et al., 2011). Despite this progress, assessing impacts from mitigation options across these categories is complex and uncertain (De Boer et al., 2011). Applications of LCSA to actual case studies are limited, but one paper that applied LCSA to three different used-cookingoil-collection systems noted the difficulty of quantifying social components of the assessment and relating them to a functional unit, which itself posed a challenge for comparing inventories across the collection systems analyzed (Vinyes, OliverSolà, Ugaya, Rieradevall, \& Gasol, 2013).

\section{Food Systems Assessments}

Food systems assessment is the most specifically food systems-oriented framework discussed here, as it has the explicit goal of evaluating and understanding the characteristics of a given food system to improve it. Food systems assessments provide a complex look at multiple dimensions of operating food systems using quantitative and qualitative data (Lacagnina, Hughner, Barroso, Hall, \& Wharton, 2017; LaClair, 2016). They operate from a systemslevel perspective, including multiple data sources and methods, and should involve community stakeholders and representatives throughout the process both to build trust and to reveal gaps and opportunities (LaClair, 2016). Food systems planning assessment tools include foodshed assessments, land inventory food assessments, comprehensive food systems assessments, community food security assessments, community food asset mapping, food desert assessments, local food economy assessments, and food industry assessments (Freedgood, Pierce-Quiñonez, \& Meter, 2011).

Asset mapping quantifies and spatially maps physical and other 'assets' in a community that promote community-driven values in relation to food. Asset maps can, for example, identify locations of farmers' markets and other local foods programs, note which of these locations support the purchase of healthy foods using food assistance programs (e.g., Supplemental Nutrition Assistance Program 
(SNAP), Special Supplemental Program for Women, Infants, and Children (WIC)), and provide information on health- or sustainability-related services provided in a specified region.

Food systems assessments also often include qualitative and quantitative data collection among a variety of stakeholders who represent key areas of food systems. These stakeholders include producers, advocates, decision-makers, corporate and other business interests, and consumers themselves in order to consider the competing frames from which stakeholders value aspects of food systems and their outcomes. Methods used include interviews, focus groups, and sometimes other ethnographic-type methodologies such as participant observations, field notes, and surveys (Lacagnina et al., 2017; LaClair, 2016).

Finally, quantitative data collection and analysis of health and food security-related indicators might also be incorporated in food systems assessments. Key data may include rates of household food security, obesity and overweight, death, chronic disease (in particular cardiovascular disease, type 2 diabetes, and perhaps some forms of cancer), and healthy food access (which can include measures of food outlet density in a given area or even evaluation of food product mixes within food outlets in a given area), to name a few.

Health impact assessment is another tool that can be used for informing agriculture, food, and nutrition decisions (Cowling, Lindberg, Dannenberg, Neff, \& Pollack, 2017). Likewise, a food policy audit can be performed to directly assess the presence or absence of important foodbased policy provisions related to health, economic development, environment, equity, and land conservation (O'Brien \& Denckla Cobb, 2012).

Data from these various assessment tools, along with asset mapping, can provide a richer understanding of sociocultural context as well as opportunities for community-driven improvements to food systems. They further can be leveraged to balance contending demands on food systems outcomes in order to plan for a more holistic vision of the future of local, regional, or larger scale food systems operations. As such, food systems assessments have been developed in multiple locations across the country in service of a host of different interests in food systems operations and outcomes (Lacagnina et al., 2017; LaClair, 2016; McFadden et al., 2016).

\section{Sustainable Materialism}

Sustainable materialism incorporates socio-political concerns in ways many methodologies cannot. It focuses on changing everyday practices of circulation, including in food systems, to advance collective provision of basic needs, recognize the power in the circulation of things, information, and individuals, and acknowledge human immersion in non-human natural systems (Schlosberg \& Coles, 2016). Interpreting the local foods movement through the lens of sustainable materialism creates an opportunity for a more holistic analysis that couples quantitative and qualitative methodologies and concepts.

A recent conceptual expansion of the growing interest in local food systems from the perspectives of consumer health and environmental impact was proposed by Schlosberg and Coles (2016). Moving beyond the fundamental notion of ethical consumerism as an individual-level approach to concerns about lifestyle and environment, they describe the growth of community commitments to alternative consumerism in the form of collective movements. These movements, generally characterized as sustainable materialism, include an implicit or explicit political motivation to reconceive materialistic, consumer behaviors as a form of ethical environmental activism (Schlosberg \& Coles, 2016). Sustainable materialism includes three primary tenets as described by Schlosberg and Coles (2016):

1. Collectivist movements concerned with the material flow from nature to human realm as products and services

2. Resistance against conventional flows considered damaging to the self, community, and environment from which materials came

3. Engagement in alternative flows better aligned with self, community, and environment

Together, these tenets suggest first that individual-level actions can and are being elevated to 
the level of movements, demonstrated by the increase in local foods programs such as CSA's and farmers' markets. Second, they imply the possibility that LCA-style data, in combination with qualitative or mixed methods approaches, could inform interested communities about the types of material flows that best align with their normative concerns about food systems. Findings from research regarding how programs operate and what they produce could inform how communities engage with local food programs. Engaging in actions such as these could be considered tools to move communities towards the preferred futures that are often identified through backcasting and scenario-building exercises.

\section{Backecasting and Scenario-Building}

A widely applicable framework for envisioning a desired future for a food system and taking steps to make it a reality is backcasting and scenario building (Heinrichs, Martens, Michelsen, \& Wiek, 2016). Regardless of the outcome desired, backcasting allows stakeholders to envision practical steps towards that future. Backcasting and scenariobuilding is a key toolset that provides insight into the interests and values of those focused on the complexities of food systems operations in a sustainable world (Heinrichs et al., 2016). Backcasting provides an inclusive framework through which communities and stakeholders can come to a shared vision of future outcomes of food systems, then 'backcast' to present day in order to explore what scenarios and steps are necessary to work towards that future vision. The process, with appropriate and comprehensive input, can address the complexity of competing visions and values while taking into consideration real-world assets, opportunities, and barriers to achieving some future food systems goal. As such, this framework sets the stage for a broader and deeper consideration of individuals' and communities' roles in food systems optimization for single or multiple goals.

\section{Mutual Benefit Solutions}

Despite the conflict seen between efficiency and resilience, there are opportunities for solutions that promote both or at least advance one without deterring the other. Such multifinal solutions by na- ture are restricted to a smaller solution space compared to agendas promoting one goal without concern for the other (Köpetz, Faber, Fishbach, \& Kruglanski, 2011).

One such recently published example employed the use of LCA with dietary data related to protein quality, the digestible indispensable amino acid score (DIAAS) (Berardy et al., 2019). DIAAS has recently been adopted by the Food and Agriculture Organization of the United Nations in order to evaluate protein bioavailability better to identify protein foods that best meet the needs of a growing population, and thus help to avert problems of malnutrition and food insecurity (FAO Expert Consultation, 2013). The integration of DIAAS and serving size into the evaluation of LCA results rather than just providing a new functional unit allowed for representation of food characteristics important to a variety of stakeholder groups and for consideration of quality and potential health impacts alongside efficiency concerns and GWP.

An excellent example of a solution advancing both efficiency and resilience goals is the reduction of food waste, but significant work remains to be done in advancing that agenda. Specifically, household food waste behavior is a neglected topic with a strong need for future research (Porpino, 2016). Sustainable intensification of agricultural production systems is another solution that seeks to advance both efficiency and resilience by balancing demand moderation with yield increases while also preserving biodiversity, protecting the environment, and applying appropriate location-specific and rigorously tested techniques best suited for a given situation (Garnett et al., 2013).

\section{Conclusions}

LCA provides a tool well-suited to support advances in efficiency, particularly with regard to the prevailing commodity agriculture system, but illsuited to support advances in resilience, encourage systematic transformation, or deal with the complexities, ambiguity, and variability inherent in food systems. Problems in determining system boundaries, appropriate functional units, and geospatially and temporally based variations hinder the utility of LCA when applied to food. Therefore, policy- 
makers should not rely solely on LCA results when making decisions in all cases, and researchers should not make broad sustainability claims based on LCA alone. Multiple other frameworks, including sustainable materialism, food systems assessments, and backcasting with scenario-building, exist that provide more holistic evaluations or frameworks supportive of transformation. These methods can complement LCA through providing a better qualitative understanding of the environmental consequences beyond a per-functional-unit basis. It is only through combining methods that a holistic understanding of the sustainability implications of food systems decisions can be ascertained. Reducing food waste and sustainable intensification are two paths forward that can advance efficiency and resilience simultaneously.

\section{References}

Andersson, K. (2000). LCA of food products and production systems. The International Journal of Life Cycle Assessment, 5(4), 239-248. https://doi.org/10.1007/BF02979367

Baroni, L., Cenci, L., Tettamanti, M., \& Berati, M. (2007). Evaluating the environmental impact of various dietary patterns combined with different food production systems. European Journal of Clinical Nutrition, 61(2), $279-286$. https://doi.org/10.1038/sj.ejcn.1602522

Bennett, E., Carpenter, S. R., Gordon, L. J., Ramankutty, N., Balvanera, P., Campbell, B., ... Spierenburg, M. (2014). Toward a more resilient agriculture. Solutions, 5(5), 65-75. Retrieved from https://www.thesolutionsjournal.com/article/toward-a-more-resilient-agriculture/

Berardy, A. (2015). Finding the future of food: Sustainable consumption lessons from and for veganism. (Doctoral dissertation, Arizona State University). Retrieved from http://hdl.handle.net/2286/R.A.150608

Berardy, A., Johnston, C. S., Plukis, A., Vizcaino, M., \& Wharton, C. (2019). Integrating protein quality and quantity with environmental impacts in life cycle assessment. Sustainability, 11(10), 2747. https://doi.org/10.3390/su11102747

Berlin, J. (2002). Environmental life cycle assessment (LCA) of Swedish semi-hard cheese. International Dairy Journal, 12(11), 939-953. https://doi.org/10.1016/S0958-6946(02)00112-7

Brundtland, G. H. (1987). Report of the World Commission on Environment and Development: Our Common Future. Retrieved from https://sustainabledevelopment.un.org/content/documents/5987our-common-future.pdf

Campbell, T. C., \& Campbell II, T. M. (2006). The China Study. Dallas, TX: BenBella Books, Inc.

Carlsson-Kanyama, A. (1998). Climate change and dietary choices - How can emissions of greenhouse gases from food consumption be reduced? Food Policy, 23(3-4), 277-293. https://doi.org/10.1016/S0306-9192(98)00037-2

Carrera-Bastos, P., Fontes-Villalba, M., O’Keefe, J. H., Lindeberg, S., \& Cordain, L. (2011). The western diet and lifestyle and diseases of civilization. Research Reports in Clinical Cardiology, 2, 15-35. https://doi.org/10.2147/RRCC.S16919

Cederberg, C., \& Stadig, M. (2003). System expansion and allocation in life cycle assessment of milk and beef production. International Journal of Life Cycle Assessment, 8(6), 350-356. https://doi.org/10.1007/BF02978508

Chatzisymeon, E., Foteinis, S., \& Borthwick, A. G. L. (2017). Life cycle assessment of the environmental performance of conventional and organic methods of open field pepper cultivation system. International Journal of Life Cycle Assessment, 22(6), 896-908. https://doi.org/10.1007/s11367-016-1204-8

Costello, C., Xue, X., \& Howarth, R. (2015). Comparison of production-phase environmental impact metrics derived at the farm- and national-scale for United States agricultural commodities. Environmental Research Letters, $10(11), 114004$. https://doi.org/10.1088/1748-9326/10/11/114004

Cowling, K., Lindberg, R., Dannenberg, A. L., Neff, R. A., \& Pollack, K. (2017). Review of health impact assessments informing agriculture, food, and nutrition policies, programs, and projects in the United States. Journal of Agriculture, Food Systems, and Community Development, 7(3), 139-157. https://doi.org/10.5304/jafscd.2017.073.009

Curran, M., de Baan, L., De Schryver, A. M., van Zelm, R., Hellweg, S., Koellner, T., Sonnemann, G., \& Huijbregts, M. A. J. (2010). Toward meaningful end points of biodiversity in life cycle assessment. Environmental Science \& Technology, 45(1), 70-79. https://doi.org/10.1021/es101444k

Dalgaard, R., Schmidt, J., Halberg, N., Christensen, P., Thrane, M., \& Pengue, W. A. (2008). LCA of soybean meal. International Journal of Life Cycle Assessment, 13, Art. 240. https://doi.org/10.1065/lca2007.06.342 
De Boer, I. J. M., Cederberg, C., Eady, S., Gollnow, S., Kristensen, T., Macleod, M., ... Zonderland-Thomassen, M. A. (2011). Greenhouse gas mitigation in animal production: Towards an integrated life cycle sustainability assessment. Current Opinion in Environmental Sustainability, 3(5), 423-431. https://doi.org/10.1016/i.cosust.2011.08.007

de Vries, M., \& de Boer, I. J. M. (2010). Comparing environmental impacts for livestock products: A review of life cycle assessments. Livestock Science, 128(1-3), 1-11. https://doi.org/10.1016/j.livsci.2009.11.007

Drewnowski, A., \& Popkin, B. (1997). The nutrition transition: New trends in the global diet. Nutrition Reviews, 55(2), 3143. https://doi.org/10.1111/j.1753-4887.1997.tb01593.x

Du, S., Mroz, T. A., Zhai, F., \& Popkin, B. M. (2004). Rapid income growth adversely affects diet quality in Chinaparticularly for the poor! Social Science \& Medicine, 59(7), 1505-1515.

https://doi.org/10.1016/j.socscimed.2004.01.021

Eakin, H., Connors, J. P., Wharton, C., Bertmann, F., Xiong, A., \& Stoltzfus, J. (2017). Identifying attributes of food system sustainability: Emerging themes and consensus. Agriculture and Human Values, 34(3), 757-773. https://doi.org/10.1007/s10460-016-9754-8

Ellingsen, H., \& Aanondsen, S. A. (2006). Environmental impacts of wild caught cod and farmed salmon - A comparison with chicken (7 pp). The International Journal of Life Cycle Assessment, 11(1), 60-65. https://doi.org/10.1065/lca2006.01.236

Ericksen, P. J. (2008). Conceptualizing food security for global environmental change research. Global Environmental Change, 18(1), 234-245. https://doi.org/10.1016/j.gloenvcha.2007.09.002

Food and Agriculture Organization of the United Nations (FAO). (2006). Livestock's long shadow - environmental issues and options. Retrieved from the Food and Agriculture Organization of the United Nations website: http://www.fao.org/3/a-a0701e.pdf

FAO. (2011). Global food losses and food waste - Extent, causes and prevention. Rome. Retrieved from http://www.fao.org/3/a-i2697e.pdf

FAO Expert Consultation. (2013). Dietary protein quality evaluation in buman nutrition. Rome. Retrieved from http://www.fao.org/ag/humannutrition/35978-02317b979a686a57aa4593304ffc17f06.pdf

Foteinis, S., \& Chatzisymeon, E. (2016). Life cycle assessment of organic versus conventional agriculture. A case study of lettuce cultivation in Greece. Journal of Cleaner Production, 112(4), 2462-2471. https://doi.org/10.1016/j.jclepro.2015.09.075

Freedgood, J., Pierce-Quiñonez, M., \& Meter, K. (2011). Emerging assessment tools to inform food system planning. Journal of Agriculture, Food Systems, and Community Development, 2(1), 83-104. https://doi.org/10.5304/jafscd.2011.021.023

Garnett, T. (2014). Three perspectives on sustainable food security: Efficiency, demand restraint, food system transformation. What role for life cycle assessment? Journal of Cleaner Production, 73, 10-18. https://doi.org/10.1016/i.jclepro.2013.07.045

Garnett, T., Appleby, M. C., Balmford, A., Bateman, I. J., Benton, T. G., Bloomer, P., ... Godfray, H. C. J. (2013). Sustainable intensification in agriculture: Premises and policies. Science, 341(6141), 33-34. https://doi.org/10.1126/science.1234485

Gava, O., Bartolini, F., Venturi, F., Brunori, G., Zinnai, A., \& Pardossi, A. (2019). A reflection of the use of the life cycle assessment tool for agri-food sustainability. Sustainability, 11(1). https://doi.org/10.3390/su11010071

Geyer, R., Lindner, J. P., Stoms, D. M., Davis, F. W., \& Wittstock, B. (2010). Coupling GIS and LCA for biodiversity assessments of land use. The International Journal of Life Cycle Assessment, 15(7), 692-703. https://doi.org/10.1007/s11367-010-0199-9

Gödecke, T., Stein, A. J., \& Qaim, M. (2018). The global burden of chronic and hidden hunger: Trends and determinants. Global Food Security, 17, 21-29. https://doi.org/10.1016/j.gfs.2018.03.004

Godfray, H. C. J., Beddington, J. R., Crute, I. R., Haddad, L., Lawrence, D., Muir, J. F., ... Toulmin, C. (2010). Food security: The challenge of feeding 9 billion people. Science, 327(5967), 812-818. https://doi.org/10.1126/science.1185383 
Goolsby, D. A., \& Battaglin, W. A. (2000). Nitrogen in the Mississippi Basin_Estimating sources and predicting flux to the Gulf of Mexico (Report No. 135-00). USGS Science for a Changing World Fact Sheet. Retrieved from https://pubs.usgs.gov/fs/2000/0135/report.pdf

Guinée, J. B., Heijungs, R., Huppes, G., Zamangni, A., Masoni, P., Buonamici, R., Ekvall, T., \& Rydberg, T. (2011). Life cycle assessment: Past, present, and future. Environmental Science \& Technology, 45(1), 90-96. https://doi.org/10.1021/es101316v

Heinrichs, H., Martens, P., Michelsen, G., \& Wiek, A. (Eds.). (2016). Sustainability Science - An Introduction. Dordrecht: Springer. https://doi.org/10.1007/978-94-017-7242-6

Heller, M. C., \& Keoleian, G. a. (2003). Assessing the sustainability of the US food system: a life cycle perspective. Agricultural Systems, 76(3), 1007-1041. https://doi.org/10.1016/S0308-521X(02)00027-6

Jacka, F. N., Pasco, J. A., Mykletun, A., Williams, L. J., Hodge, A. M., O’Reilly, S. L., .. Berk, M. (2010). Association of western and traditional diets with depression and anxiety in women. American Journal of Psychiatry, 167(3), 305-311. https://doi.org/10.1176/appi.ajp.2009.09060881

Jungbluth, N., Tietje, O., \& Scholz, R. (2000). Food purchases: Impacts from the consumers' point of view investigated with a modular LCA. The International Journal of Life Cycle Assessment, 5, 134-142. https://doi.org/10.1007/BF02978609

Kim, S., Dale, B. E., \& Jenkins, R. (2009). Life cycle assessment of corn grain and corn stover in the United States. The International Journal of Life Cycle Assessment, 14(2), 160-174. https://doi.org/10.1007/s11367-008-0054-4

Kanoski, S. E., \& Davidson, T. L. (2011). Western diet consumption and cognitive impairment: Links to hippocampal dysfunction and obesity. Physiology \& Behavior, 103(1), 59-68. https://doi.org/10.1016/j.physbeh.2010.12.003

Kloepffer, W. (2008). Life cycle sustainability assessment of products. International Journal of Life Cycle Assessment, 13(2), 89-94. https://doi.org/10.1065/lca2008.02.376

Köpetz, C., Faber, T., Fishbach, A., \& Kruglanski, A. W. (2011). The multifinality constraints effect: How goal multiplicity narrows the means set to a focal end. Journal of Personality and Social Psychology, 100(5), 810-826. https://doi.org/10.1037/a0022980

Korhonen, J., \& Seager, T. (2008). Beyond eco-efficiency: A resilience perspective. Business Strategy and the Environment, 17(7), 411-419. Retrieved from https://doi.org/10.1002/bse.635

Lacagnina, G., Hughner, R., Barroso, C., Hall, R., \& Wharton, C. (2017). Supply chain barriers to healthy, affordable produce in Phoenix-area food deserts. Journal of Food Distribution Research, 48(3), 1-15. https://doi.org/10.22004/ag.econ.274592

LaClair, B. (2016). From farm to table: A Kansas guide to communty food assessment. Retrieved from http://www.ruralgrocery.org/resources/KS Food Assessment Guide final.pdf

Lassey, K. R. (2007). Livestock methane emission: From the individual grazing animal through national inventories to the global methane cycle. Agricultural and Forest Meteorology, 142(2-4), 120-132. https://doi.org/10.1016/j.agrformet.2006.03.028

Leinonen, I., Williams, A. G., Wiseman, J., Guy, J., \& Kyriazakis, I. (2012). Predicting the environmental impacts of chicken systems in the United Kingdom through a life cycle assessment: Broiler production systems. Poultry Science, 91(1), 8-25. https://doi.org/10.3382/ps.2011-01634

MacMillan Uribe, A. L., Winham, D. M., \& Wharton, C. M. (2012). Community supported agriculture membership in Arizona. An exploratory study of food and sustainability behaviours. Appetite, 59(2), 431-436. https://doi.org/10.1016/j.appet.2012.06.002

Manzel, A., Muller, D. N., Hafler, D. A., Erdman, S. E., Linker, R. A., \& Kleinewietfeld, M. (2014). Role of "western diet" in inflammatory autoimmune diseases. Current Allergy and Asthma Reports, 14(1), 1-13. https://doi.org/10.1007/s11882-013-0404-6

Mattick, C. S., Landis, A. E., Allenby, B. R., \& Genovese, N. J. (2015). Anticipatory life cycle analysis of in vitro biomass cultivation for cultured meat production in the United States. Environmental Science \& Technology, 49(19), 1194111949. https://doi.org/10.1021/acs.est.5b01614 
McFadden, D. T., Conner, D., Deller, S., Hughes, D., Meter, K., Morales, A., ... Tropp, D. (2016). The economics of local food systems: A toolkit to guide community discussions, assessments, and choices. U.S. Department of Agriculture, Agricultural Marketing Service. Retrieved from https://www.ams.usda.gov/sites/default/files/media/Toolkit\%20Designed\%20FINAL\%203-22-16.pdf

McMichael, P. (2001). The impact of globalisation, free trade and technology on food and nutrition in the new millennium. Proceedings of the Nutrition Society, 60(02), 215-220. https://doi.org/10.1079/PNS200088

Mejia, A., Harwatt, H., Jaceldo-Siegl, K., Sranacharoenpong, K., Soret, S., \& Sabaté, J. (2018). Greenhouse gas emissions generated by tofu production: A case study. Journal of Hunger and Environmental Nutrition, 13(1), 131-142. https://doi.org/10.1080/19320248.2017.1315323

Mollenhorst, H., Berentsen, P. B. M., \& De Boer, I. J. M. (2006). On-farm quantification of sustainability indicators: an application to egg production systems. British Poultry Science, 47(4), 405-417. https://doi.org/10.1080/00071660600829282

Morelli, B., Hawkins, T. R., Niblick, B., Henderson, A. D., Golden, H. E., Compton, J. E., Cooter, E. J., Bare, J. C. (2018). Critical review of eutrophication models for life cycle assessment. Environmental Science \& Technology, 52(17), 9562-9578. https://doi.org/10.1021/acs.est.8b00967

Notarnicola, B., Sala, S., Anton, A., McLaren, S. J., Saouter, E., \& Sonesson, U. (2017). The role of life cycle assessment in supporting sustainable agri-food systems: A review of the challenges. Journal of Cleaner Production, 140(2), 399-409. https://doi.org/10.1016/i.jclepro.2016.06.071

O’Brien, J., \& Denckla Cobb, T. (2012). The Food Policy Audit: A new tool for community food system planning. Journal of Agriculture, Food Systems, and Community Development, 2(3), 177-191. https://doi.org/10.5304/jafscd.2012.023.002

Pizzol, M. (2015). Life cycle assessment and the resilience of product systems. Journal of Industrial Ecology, 19(2), 296-306. https://doi.org/10.1111/jiec.12254

Plant Based Foods Association. (2018a). 2018 U.S. retail sales data for plant-based foods. Retrieved from https://plantbasedfoods.org/consumer-access/nielsen-data-release-2018/

Porpino, G. (2016). Household food waste behavior: Avenues for future research. Journal of the Association for Consumer Research, 1(1), 41-51. https://doi.org/10.1086/684528

Prado-Lopez, V., Seager, T. P., Chester, M., Laurin, L., Bernardo, M., \& Tylock, S. (2014). Stochastic multi-attribute analysis (SMAA) as an interpretation method for comparative life-cycle assessment (LCA). International Journal of Life Cycle Assessment, 19(2), 405-416. https://doi.org/10.1007/s11367-013-0641-x

Rabalais, N. N., Turner, R. E., \& Wiseman, W. J. (2002). Gulf of Mexico hypoxia, a.k.a. "the dead zone." Annual Review of Ecology and Systematics, 33(1), 235-263. https://doi.org/10.1146/annurev.ecolsys.33.010802.150513

Risku-Norja, H., Kurppa, S., \& Helenius, J. (2009). Dietary choices and greenhouse gas emissions-assessment of impact of vegetarian and organic options at national scale. Progress in Industrial Ecology, An International Journal, 6(4), 340-354. https://doi.org/10.1504/PIE.2009.032323

Robinson, C. \& Antoniou, M. (2018). The Impossible Burger: Boon or risk to health and environment. GMO Science. Retrieved from https://www.gmoscience.org/impossible-burger-boon-risk-health-environment/

Rockström, J., Steffen, W., Noone, K, Persson, A., Chapin III, F. S., Lambin, E. F., Lenton, T. M., ... Foley, J. A. (2009). A safe operating space for humanity. Nature, 461, 472-475. Retrieved from http://www.nature.com/nature/journal/v461/n7263/full/461472a.html

Rodríguez, C., Ciroth, A., \& Srocka, M. (2014, October). The importance of regionalized LCLA in agricultural LCA - new software implementation and case study. International Converance LCA of Food, San Francisco, CA. Retrieved from https://www.openlca.org/wp-content/uploads/2015/11/3_LCA-Food-2014_Importance-of-regionalized-LCIAin-agricultural-LCA.pdf

Roy, P., Nei, D., Orikasa, T., Xu, Q., Okadome, H., Nakamura, N., \& Shiina, T. (2009). A review of life cycle assessment (LCA) on some food products. Journal of Food Engineering, 90(1), 1-10.

https://doi.org/10.1016/i.jfoodeng.2008.06.016 
Sanfilippo, S., Raimondi, A., Ruggeri, B., \& Fino, D. (2012). Dietary vs. transport: an analysis of environmental burdens pertaining to a typical workday. International Journal of Consumer Studies, 36(2), 133-140. https://doi.org/10.1111/j.1470-6431.2011.01079.x

Scarborough, P., Appleby, P. N., Mizdrak, A., Briggs, A. D. M., Travis, R. C., Bradbury, K. E., \& Key, T. J. (2014). Dietary greenhouse gas emissions of meat-eaters, fish-eaters, vegetarians and vegans in the UK. Climatic Change, 125(2), 179-192. https://doi.org/10.1007/s10584-014-1169-1

Schlosberg, D., \& Coles, R. (2016). The new environmentalism of everyday life: Sustainability, material flows and movements. Contemporary Political Theory, 15(2), 160-181. https://doi.org/10.1057/cpt.2015.34

Seager, T., Selinger, E., \& Wiek, A. (2012). Sustainable engineering science for resolving wicked problems. Journal of Agricultural and Environmental Ethics, 25(4), 467-484. https://doi.org/10.1007/s10806-011-9342-2

Seager, T. P., \& Theis, T. L. (2002). A uniform definition and quantitative basis for industrial ecology. Journal of Cleaner Production, 10(3), 225-235. https://doi.org/10.1016/S0959-6526(01)00040-3

Singh, P. N., Arthur, K. N., Orlich, M. J., James, W., Purty, A., Job, J. S., Rajaram, S., Sabaté, J. (2014). Global epidemiology of obesity, vegetarian dietary patterns, and noncommunicable disease in Asian Indians. American Journal of Clinical Nutrition, 100(SUPPL. 1), 359-364. https://doi.org/10.3945/ajcn.113.071571

Sobal, J., Khan, L. K., \& Bisogni, C. (1998). A conceptual model of the food and nutrition system. Social Science \& Medicine, 47(7), 853-863. Retrieved from https://doi.org/10.1016/S0277-9536(98)00104-X

Thomassen, M. A., Dalgaard, R., Heijungs, R., \& de Boer, I. (2008). Attributional and consequential LCA of milk production. International Journal of Life Cycle Assessment, 13(4), 339-349. https://doi.org/10.1007/s11367-008-0007-y

Tuomisto, H. L., \& de Mattos, M. J. T. (2011). Environmental impacts of cultured meat production. Environmental Science \& Technology, 45(14), 6117-6123. https://doi.org/10.1021/es200130u

United States Environmental Protection Agency. (n.d.). Basic information about landfill gas. U.S. Environmental Protection Agency Landfill Methane Outreach Program. Retrieved March 12, 2019, from https://www.epa.gov/lmop/basic-information-about-landfill-gas

Uzogara, S. G. (2000). The impact of genetic modification of human foods in the 21st century: A review. Biotechnology Advances, 18(3), 179-206. Retrieved from https://doi.org/10.1016/S0734-9750(00)00033-1

Vermeulen, S. J., Campbell, B. M., \& Ingram, J. S. I. (2012). Climate change and food systems. Annual Review of Environment and Resources, 37(1), 195-222. https://doi.org/10.1146/annurev-environ-020411-130608

Vinyes, E., Oliver-Solà, J., Ugaya, C., Rieradevall, J., \& Gasol, C. M. (2013). Application of LCSA to used cooking oil waste management. International Journal of Life Cycle Assessment, 18(2), 445-455. https://doi.org/10.1007/s11367-012-0482-z

Weber, C. L., \& Matthews, H. S. (2008). Food-miles and the relative climate impacts of food choices in the United States. Environmental Science \&o Technology, 42(10), 3508-3513. https://doi.org/10.1021/es702969f

Weidema, B., Wenzel, H., Petersen, C., \& Hansen, K. (2004). The product, functional unit and reference flows in LCA (Environmental News No. 70). Retrieved from http://lca-center.dk/wp-content/uploads/2015/08/The-product-functional-unit-and-reference-flows-in-LCA.pdf

Willett, W., Rockström, J., Loken, B., Springmann, M., Lang, T., Vermeulen, S., .. Murray, C. J. L. (2019). Food in the Anthropocene: The EAT-Lancet Commission on healthy diets from sustainable food systems. The Lancet, 393(10170), 447-492. https://doi.org/10.1016/S0140-6736(18)31788-4

Williams, A. G., Audsley, E., \& Sandars, D. L. (2006). Determining the environmental burdens and resource use in the production of agricultural and horticultural commoditites. Main report. Bedford: Cranfield University \& Defra.

Worstell, J., \& Green, J. (2017). Eight qualities of resilient food systems: Toward a Sustainability/Resilience Index. Journal of Agriculture, Food Systems, and Community Development, 7(3), 1-19. https://doi.org/10.5304/jafscd.2017.073.001

Xue, X., \& Landis, A. E. (2010). Eutrophication potential of food consumption patterns. Environmental Science \& Technology, 44(16), 6450-6456. https://doi.org/10.1021/es9034478 